Research Article

\title{
Development of QuEChERS Method for the Determination of Polycyclic Aromatic Hydrocarbons in Smoked Meat Products Using GC-MS from Qatar
}

\author{
Hussain Al-Thaiban, Nada Al-Tamimi, and Murad Helaleh \\ Anti Doping Lab-Qatar, Toxicology Multipurpose laboratory, P.O. Box 27775, Doha, Qatar \\ Correspondence should be addressed to Murad Helaleh; mrhelala@yahoo.com
}

Received 27 December 2017; Accepted 24 June 2018; Published 18 July 2018

Academic Editor: Valdemar Esteves

Copyright (c) 2018 Hussain Al-Thaiban et al. This is an open access article distributed under the Creative Commons Attribution License, which permits unrestricted use, distribution, and reproduction in any medium, provided the original work is properly cited.

\begin{abstract}
A simple and fast method for the determination of PAHs in smoked meat samples was described. The QuEChERS (Z-Sep) procedure was used for sample preparation. Gas chromatograph-mass spectrometer with electron ionization (EI) was used to separate and detect the PAHs. All 16 common PAHs were analyzed successfully. Matrix-matched calibration was applied. Spiked samples were performed at $1 \mathrm{ng} / \mathrm{g}(n=10)$ and $10 \mathrm{ng} / \mathrm{g}(n=10)$ for two days. Overall recoveries of PAHs were within 74 to $117 \%$, with RSDs within 1.15 to $37.57 \%$ and 1 and $10 \mathrm{ng} / \mathrm{g}$ wet weight for first and second day, respectively. In most of the analyzed smoked meat samples, there were no exceeded levels compared to the maximum levels declared by Commission Regulation (EU) number $835 / 2011$. The method can be recommended for routine analysis for laboratories having a large number of samples.
\end{abstract}

\section{Introduction}

PAHs represents a group of organic compounds (hydrophobic) consisting of two or more fused aromatic rings that are ubiquitous pollutants and those can be generated during food processing [1]. PAHs containing five or more rings are considered having potential carcinogenic and genotoxic to humans and regarded as concerned to public health [2-4]. Therefore, exposure to PAHs is recommended to be as low as possible [5]. Diet is considered to be one of the highest exposures to PAHs to the most population in different countries and counts to be more than $90 \%[2,6,7]$. However, high level of PAHs is not usually detected in raw foods [7].

PAHs are widely distributed in the environment and remains for a long time [8]. Benzo[a]pyrene $(\mathrm{B}[\mathrm{a}] \mathrm{P})$ is carcinogenic and mutagenic [9] and may cause a substantial contributed to burden cancer in human [10]. However, according to scientific committee on food (SCF) [11], B [a]P was considered as a marker for the occurrence and impact of PAHs carcinogenic in food.
PAH compounds those containing five or more aromatic rings are known as "heavy molecular weight (HMW)" PAHs and those with less than five rings are known as "light molecular weight" (LMW) PAHs. Heavy and light PAHs are nonpolar compounds, showing high lipophilic nature. However, HMW PAHs is more toxic than LMW PAHs [12]. Other groups of PAHs which are not defined as carcinogens may act as synergists. As a general concept, PAHs are present in a mixture and are regarded the priority organic pollutants [12]. The fact that PAHs are present in food insists their control in food is necessary [13].

A method for determining the PAHs levels in commercial smoked meat and fish products from polish market was reported [14], PAHs were determined in grilled meat [15], in smoked fish [16] and B [a]P in smoked meat products $[17,18]$,in meat products smoked with different types of wood and smoking spices [19], and in Swedish smoked meat and fish [20]. PAHs in smoked ham produced at household in Serbia were reported [21]. A study was reported for the evaluation of the health risk of long-term exposure to PAHs in daily intake of smoked meat in Southwest China [22]. 
There are different routes of contamination on food, which include and not limited to (i) packing materials and thermal processing of food from animal origins [23] and even during home preparation and (ii) direct deposition of PAHs from weathering of fruits and vegetables [24].

The principle of sample preparation is to remove the complexities of the matrix from the sample and to make it suitable for qualitative and quantitative analysis [25]. Extraction techniques such as Soxhlet can be simple, which consumes large solvent volumes and takes long extraction times. However, the cleanup techniques to remove residues such as lipids are challenging. Standard methods for cleanup such as GPC [26], florisil [27], and silica gel [28], which required an extensive quantity of reagents, solvents, and materials, are available in the literature. A challenge for rapid extraction and clean-up method has become essential, in order to minimize the sample preparation costs and minimize consumable costs. Quenchers method was first developed by Anastassiades et al., to provide a rapid, inexpensive, and fast method for analyzing pesticides residues in fruits and vegetables [29]. The method was extended to extract pesticide and cleanup the extract from fatty foods (e.g., avocados, milk, and eggs) [30]. Quenchers method has been shown to efficiently analyze fish fillets [31-33] and shrimp [34]. The nature of Quenchers sample preparation is promising and permits its use for extraction and cleanup, and it is efficiently applicable for the analysis of wide matrices.

Quantitative analysis of PAHs from a complex matrices such as smoked meat faces three major challenges: (i) the occurrence of most PAHs at trace levels (i.e., ppb levels), (ii) the coextract of many other components from the matrices with PAHs, which leads to difficult identification in chromatographic spectrum, and (iii) the structural similarity and many of PAHs occur as isomers, which again leads to identification problem in individual PAHs [35].

Quenchers techniques replaced the complications of common, standard extraction techniques, and they provide a simple protocol for sample handling [36]. Acetonitrile was used as an extraction solvent in QuEChERS instead of acetone, which is thought to be an excellent separator from water, after the addition of salts [37, 38]. Moreover, the cleanup protocols are adopted to effectively remove the matrix-matched materials such as polar pigment, fatty acids, organic compounds, and sugar [29].

There was a growing interest in QuEChERS among researchers all over the world; the need for further investigation is mandatory for researchers in order to facilitate and develop rapid, efficient, and effective methods for different complicated matrices.

Quenchers method is basically based on extraction with acetonitrile partitioned from an aqueous matrix using $\mathrm{MgSO}_{4}$ and $\mathrm{NaCl}$ followed by cleanup using (d-SPE) with $\mathrm{MgSO}_{4}$ and analysis by GC-MS. Labelled d-PAHs can be used as an internal standard to compensate the analyte loss and matrix effect on chromatographic response.

One of the main obstacles in the determination of fatty food is the high-fat content (e.g., lipids, triglycerides, and fatty acids). However, the removal of lipids is important to maintain the GC system and also to allow the low detection limits (LOD). The sensitivity of the method was confirmed by the ability to detect low PAHs concentrations at the allowable permitted levels. Lipids may have severe effects, such as reproducibility, robustness, and recovery, on analyzing PAHs by GC-MS[39]. Therefore, it is essential to remove lipids prior to analyses.

The aim of the present study is to optimize and validate the applicability of Quenchers for the extraction and cleanup and finally analyzing 16 PAHs in smoked meat samples at low LOQ levels. A few studies in the literature were reported for developing an excellent analytical method utilizing QuEChERS for determining PAHs concentrations in smoked meat samples. However, both levels and distribution patterns in smoked meat product are of interest. The method was developed to cover the analysis of 2-6 rings PAHs. Precision and accuracy of the method were validated.

\section{Materials and Methods}

2.1. Chemicals. All $16 \mathrm{PAH}$ standards, naphthalene (NAP), acenaphthylene (ACNY), acenaphthene (ACN), fluorene (FL), phenanthrene (PHEN), anthracene (ANTH), fluoranthene (FLU), pyrene (PYR), benz[a]anthracene (B[a]A), chrysene (CHRY), benzo[b]fluoranthene $(\mathrm{B}[\mathrm{b}] \mathrm{F})$, benzo[k]fluoranthene $(\mathrm{B}[\mathrm{k}] \mathrm{F})$, benzo[a]pyrene $(\mathrm{B}[\mathrm{a}] \mathrm{P})$, indeno[1,2,3-cd]pyrene (I123-cd_P), dibenz[a,h]anthracene (D[ah]A), and benzo[g,h,i] perylene $(\mathrm{B}[\mathrm{ghi}] \mathrm{P})$, were purchased from Cambridge isotope laboratories (Frontage Road, Andover, MA, USA). The internal standard mixture: naphthalene_d8 (NAPH_d8), acenaphthylene_d8 (ACNY_d8), phenanthrene_d10 (PHEN_d10), fluoranthene_d10 (FLU_d10), pyrene_d10 (PYR_d10), benzo [a]pyrene_d12 (B[a]P_d12), and benzo[g,h,i]perylene_d12 (B[ghi]P_d12) were obtained from Cambridge isotope laboratories (Frontage Road, Andover, MA, USA).

Hexane was obtained from Sigma-Aldrich and dichloromethane (DCM) from fluka. $50 \mathrm{ml}$ polypropylene conical tube (Falcon) was used for the extraction. Acetonitrile (99.9\%) was obtained from Merck. Sodium chloride $(\mathrm{NaCl})$ and Magnesium Sulfate $\left(\mathrm{MgSO}_{4}\right)$ were obtained from Sigma-Aldrich. Fixed speed vortex mixer (Fisher Scientific, USA) was used for the shaking of the tubes. The centrifuge was from Thermo Scientific-SL $16 \mathrm{R}$. The QuEChERS kits used for the extraction and cleanup of meat samples were purchased from Supel TM QuE Z-Sep (12 ml tubes) (55403-U). Heating block was from Thermo Scientific-Reacti-Therm III no. TS-18824 and Turbo Vap ${ }^{\circledR}$ LV from Biotage.

2.2. Meat Samples. All smoked meat samples $(n=30)$ were purchased from Qatar local market (Qatar, Doha). All samples were weighed before being grinded, followed by dividing them into small portions by blender to homogenize them in order to (i) increase the surface area, (ii) break down the cell structure, and (iii) ensure analytical test portion representing whole samples. However, the meat samples have to be kept cold to avoid analyte break down. Finally, ground meat was stored by placing them in aluminum foil and storing at $-20^{\circ} \mathrm{C}$. 
2.3. PAHs Standard and PAH-d8. A standard mixture containing 16 PAHs solution $(2000 \mu \mathrm{g} / \mathrm{ml})$. Two working solutions were prepared $(1000 \mathrm{ng} / \mathrm{ml}$ and $50 \mathrm{ng} / \mathrm{ml})$ with DCM, capped using crimper cap and stored in the refrigerator until it is used. Deuterated PAHs concentration of $1000 \mathrm{ng} / \mathrm{ml}$ was prepared with DCM from the original PAHs surrogate cocktail $(2000 \mu \mathrm{g} / \mathrm{ml})$, and the vials were capped using crimper cap and stored in the moisture cabinet at room temperature until it is used.

2.4. Matrix-Matched Calibration. The matrix-matched calibration was used to prepare the calibration standards. It is stored in a refrigerator at $4^{\circ} \mathrm{C}$. All the standards used to prepare the matrix-spiked calibration should be taken out from the refrigerator and allowed to come at room temperature prior to use, sonicated as per the manufacturer's instructions. The matrix-matched calibration was prepared by spiking the meat sample wet weight $(2.0 \mathrm{~g})$ with standard PAHs to obtain seven calibration points $(0.5,1.0,5.0,10.0$, 20.0, 25.0, and $50.0 \mathrm{ng} / \mathrm{g}$ ) and with the d-PAHs of $20 \mathrm{ng} / \mathrm{g}$.

2.5. Preparation of PAHs QC Samples. The QC samples must be prepared from a spiking solution with the analytes of interest. The spiking should be made using standards prepared separately from those used for calibration. The QC samples were handled exactly in the same manner as the actual samples. The QC samples were analyzed by applying the same criteria for the method being evaluated. The two QC levels were at $1.0 \mathrm{ng} / \mathrm{g}$ and $10 \mathrm{ng} / \mathrm{g}$, with 10 replicates for each concentration level.

2.6. Extraction and Purification of Smoked Meat Samples. Chopped and stored smoked meat was taken out from the freezer, thawed at $4^{\circ} \mathrm{C}$ before extraction, and purified by QuEChERS method. The QuEChERS purification extract offer a fast, efficient, and accurate method for the determination of PAHs in meat samples. Two grams of smoked meat sample was added into 50 centrifuge tube and spiked with d-PAHs, mixed well, and left for $30 \mathrm{~min}$ at room temperature. Water was added $(5 \mathrm{ml})$ and homogenized, $5 \mathrm{ml}$ of ACN was added to the tube, and mixed vigorously for $1 \mathrm{~min}$. Sodium chloride ( $0.5 \mathrm{~g}$ ) and magnesium sulfate ( $3.0 \mathrm{~g})$ were added to the tube; the tube was shaken immediately for $1 \mathrm{~min}$ after adding the salts. The content was centrifuged for $10 \mathrm{~min}$ at $3400 \mathrm{rpm}$ (Temperature $=20^{\circ} \mathrm{C}$ ). The supernatant was transferred into a $15 \mathrm{ml}$ tube containing Quenchers (Z-Sep) $+500 \mathrm{mg} \mathrm{MgSO}_{4}$ and shaken for $1 \mathrm{~min}$ and centrifuged for $10 \mathrm{~min}$ at $3400 \mathrm{rpm}$ (Temperature $=20^{\circ} \mathrm{C}$ ). Finally, the extract was transferred into appropriate tubes and dried further using the heating block $\left(45^{\circ} \mathrm{C}\right)$ until the volume reaches approximately $100 \mu \mathrm{l}$. The schematic diagram of the extraction process is shown in Figure 1. Background reduction was evaluated by analysis of the extract cleaned by Z-Sep, and it shows the lowest background. The large peak eluting 7.5 to 7.9 and 19.8 to 20.5 minutes was identified or unidentified, and it did not interfere with the ions used for quantitation of PAHs.

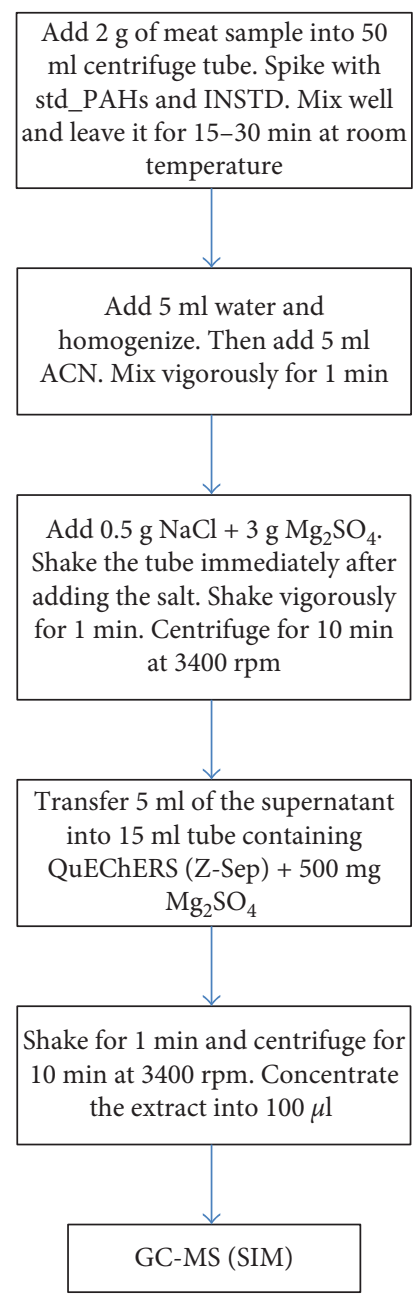

FIgURE 1: Schematic diagram for the extraction and cleanup of meat using QuEhERS method.

2.7. GC-MS Analysis. The extract was analyzed on Agilent $6890 \mathrm{~N}$ gas chromatography interfaced to Agilent 5975B mass spectrometer with electron ionization. The gas chromatography was connected with a $30 \mathrm{~m}$ HP-5MS capillary column with $0.25 \mathrm{~mm} \times 0.25 \mu \mathrm{m}$ film. Helium was used as the carrier gas. The column was maintained at a constant flow rate of $1.0 \mathrm{ml} / \mathrm{min}$, and $1 \mu \mathrm{l}$ was injected into a splitless mode and purge flow to split vent was $50 \mathrm{ml} / \mathrm{min}$ at $0.75 \mathrm{~min}$.

Ion source and quadrupole temperature were set at $280^{\circ} \mathrm{C}$ and $180^{\circ} \mathrm{C}$, respectively. Injector and transfer line were maintained at $280^{\circ} \mathrm{C}$ and $310^{\circ} \mathrm{C}$, respectively. The column temperature was initially kept at $35^{\circ} \mathrm{C}$ for $1 \mathrm{~min}$, ramped to $200^{\circ} \mathrm{C}$ at a rate of $25^{\circ} \mathrm{C} / \mathrm{min}$, ramped to $310^{\circ} \mathrm{C}$ at a rate of $8^{\circ} \mathrm{C} / \mathrm{min}$, and kept for $3.5 \mathrm{~min}$. Selected-ion monitoring (SIM) acquisition was carried out to analyze the PAHs $(\mathrm{m} / z)$ and internal standard $(\mathrm{m} / \mathrm{z})$, and comparison of the base peak of each targeted PAH and d-PAH are shown in Table 1. The target ions are the quantifier ions $(\mathrm{m} / z)$ selected for each PAHs compound and are listed in Table 1 . The qualifier ions were used for confirmation purpose. The peak was identified if the retention time varied within \pm 0.05 min compared with the calibration standard and quantified if the $S / N$ was $\geq 3$, 
TABLE 1: Retention time, quantifier ions, and qualifier ions $(\mathrm{m} / z)$ for target PAHs and d-PAHs.

\begin{tabular}{|c|c|c|c|c|}
\hline Number & Analyte & $\mathrm{RT}(\mathrm{min})$ & Quantifier ion $(\mathrm{m} / z)$ & Qualifier ion $(\mathrm{m} / \mathrm{z})$ \\
\hline 1 & Naphthalene-d8 & 6.192 & 136 & $128 / 137$ \\
\hline 2 & Naphthalene & 6.208 & 128 & $102 / 78$ \\
\hline 3 & Acenaphthylene-d8 & 7.746 & 160 & $152 / 161$ \\
\hline 4 & Acenaphthylene & 7.746 & 152 & $126 / 76$ \\
\hline 5 & Acenaphthene & 7.946 & 154 & $152 / 76$ \\
\hline 6 & Fluorene & 8.501 & 166 & $115 / 82$ \\
\hline 7 & Phenanthrene-d10 & 9.741 & 188 & $158 / 189$ \\
\hline 8 & Phenanthrene & 9.779 & 178 & $152 / 176$ \\
\hline 9 & Anthracene & 9.848 & 178 & $152 / 176$ \\
\hline 10 & Fluoranthene_D10 & 11.904 & 212 & $202 / 213$ \\
\hline 11 & Fluoranthene & 11.950 & 202 & $200 / 101$ \\
\hline 12 & Pyrene_D10 & 12.375 & 212 & $106 / 211$ \\
\hline 13 & Pyrene & 12.413 & 202 & $200 / 101$ \\
\hline 14 & Benz[a]anthracene & 15.349 & 228 & $226 / 114$ \\
\hline 15 & Chrysene & 15.453 & 228 & $226 / 114$ \\
\hline 16 & Benzo[b]fluoranthene & 18.117 & 252 & $126 / 113$ \\
\hline 17 & Benzo[k]fluoranthene & 18.178 & 252 & $126 / 113$ \\
\hline 18 & Benzo[a]pyrene_D12 & 18.814 & 264 & $132 / 252$ \\
\hline 19 & Benzo[a]pyrene & 18.883 & 252 & $126 / 113$ \\
\hline 20 & Indeno $[1,2,3$-cd $]$ pyrene & 21.409 & 276 & $138 / 274$ \\
\hline 21 & Dibenz[a,h]anthracene & 21.486 & 278 & $139 / 276$ \\
\hline 22 & Benzo[g,h,i]perylene_D12 & 21.880 & 288 & $276 / 125$ \\
\hline 223 & Benzo[g,h,i]perylene & 21.945 & 276 & $138 / 274$ \\
\hline
\end{tabular}

TABLE 2: Retention time (Rt), regression coefficient (r2), slope, intercept of the calibration curve, limit of detection (LOD), and limit of quantitation (LOQ).

\begin{tabular}{|c|c|c|c|c|c|c|c|}
\hline Compound & $\mathrm{RT}(\min )$ & $\mathrm{R} 2$ & Calibration range $(\mathrm{ng} / \mathrm{g})$ & Intercept & Slope & LOD (ng/g) & LOQ (ng/g) \\
\hline Naphthalene & 5.208 & 0.9998 & $0.5-50$ & 0.3217 & 0.0877 & 2.74 & 6.64 \\
\hline Acenaphthylene & 7.746 & 0.9996 & $0.5-50$ & 0.4983 & 0.0221 & 7.60 & 20.01 \\
\hline Acenaphthene & 7.946 & 0.9998 & $0.5-50$ & 0.0193 & 0.0078 & 2.10 & 2.77 \\
\hline Fluorene & 8.501 & 0.9981 & $0.5-50$ & 0.0335 & 0.0662 & 1.44 & 2.48 \\
\hline Phenanthrene & 9.779 & 1.0000 & $0.5-50$ & 0.0345 & 0.1582 & 1.60 & 4.21 \\
\hline Anthracene & 9.848 & 0.9998 & $0.5-50$ & 0.0495 & 0.1039 & 0.36 & 0.87 \\
\hline Fluoranthene & 11.950 & 0.9999 & $0.5-50$ & -0.0078 & 0.115 & 0.48 & 1.07 \\
\hline Pyrene & 12.413 & 1.0000 & $0.5-50$ & -0.0114 & 0.0707 & 0.50 & 0.83 \\
\hline Benz[a] anthracene & 15.349 & 1.0000 & $0.5-50$ & -0.0034 & 0.112 & 0.69 & 1.13 \\
\hline Chrysene & 15.453 & 0.9999 & $0.5-50$ & -0.0173 & 0.1231 & 0.44 & 0.62 \\
\hline Benzo[b]fluoranthene & 18.117 & 0.9995 & $0.5-50$ & 0.0841 & 0.2466 & 0.24 & 0.41 \\
\hline Benzo[k]fluoranthene & 18.178 & 0.9999 & $0.5-50$ & 0.1379 & 0.1314 & 0.53 & 1.05 \\
\hline Benzo[a]pyrene & 18.883 & 0.9996 & $0.5-50$ & -0.0163 & 0.1667 & 0.34 & 0.63 \\
\hline Indeno[ $[1,2,3-c d]$ pyrene & 21.409 & 1.0000 & $0.5-50$ & 0.0183 & 0.1884 & 0.40 & 0.75 \\
\hline Dibenz[a,h]anthracene & 21.486 & 0.9998 & $0.5-50$ & -0.0461 & 0.1885 & 0.63 & 1.22 \\
\hline Benzo[g,h,i]perylene & 21.945 & 0.9998 & $0.5-50$ & 0.1116 & 0.1448 & 1.71 & 4.41 \\
\hline
\end{tabular}

$\mathrm{LOD}=$ average concentration of the matrix blank $+3 *$ standard deviation of the matrix blank $(n=10)$; LOQ = average concentration of the matrix blank + $10 *$ standard deviation of the matrix blank $(n=10)$.

and the ratio of the quantifier ion to qualifier ion was within $\pm 20 \%$. The sample that shows low response or less than the quantification limit was considered to be nondetected.

2.8. Method Linearity. The internal standard method was applied with seven matrix-matched calibrations ranging from 0.5 to $50 \mathrm{ng} / \mathrm{g}$. The method linearity correlation coefficient $\left(r^{2}\right)$ was higher than 0.995 . The retention times $\left(R_{\mathrm{t}}\right)$, regression coefficient $\left(r^{2}\right)$, slope, and intercept of the calibration curves are summarized in Table 2. The PAH recoveries were generally higher than $70 \%$ for all PAHs. Both recoveries and precisions are acceptable and within the range for all PAH compounds. However, the proposed method meets the EU criteria that set a maximum LOD and LOQ which is equal to $0.3 \mu \mathrm{g} / \mathrm{kg}$ and $0.9 \mu \mathrm{g} / \mathrm{kg}$ for benzo[a] pyrene in food $[40,41]$. Detection and quantification limits (LODSs and LOQs) were calculated based on the analysis of the blank response. LODS was defined as the lowest concentration of the analyte in the sample that can be measured and present at a concentration above that in the blank samples (LODS $=3 * \mathrm{SD})$. LOQ was defined as the lowest concentration of the analyte that can be determined at an acceptable level of uncertainty, and usually, it was the lowest point in the calibration graph (European guideline). Analytes 
TABLE 3: : Recovery percentage, relative standard deviation (RSDs, \%) and RSDs pooled (\%) for the number of determination $(n=10)$ for each spiking level.

\begin{tabular}{|c|c|c|c|c|c|}
\hline \multirow[b]{2}{*}{ Compound } & \multicolumn{4}{|c|}{ Recovery \pm RSDs (\%) } & \multirow[b]{2}{*}{ Pooled RSD (\%) } \\
\hline & $\begin{array}{c}\text { First day } \\
1 \mathrm{ng} / \mathrm{g} \\
\text { Recovery } \pm \text { RSD } \%\end{array}$ & $\begin{array}{c}\text { Second day } \\
1 \mathrm{ng} / \mathrm{g} \\
\text { Recovery } \pm \text { RSD } \%\end{array}$ & $\begin{array}{c}\text { First day } \\
10 \mathrm{ng} / \mathrm{g} \\
\text { Recovery } \pm \text { RSD } \%\end{array}$ & $\begin{array}{c}\text { Second day } \\
10 \mathrm{ng} / \mathrm{g} \\
\text { Recovery } \pm \text { RSD } \%\end{array}$ & \\
\hline Naphthalene & $99 \pm 6$ & $104 \pm 14$ & $101 \pm 6$ & $101 \pm 6$ & 9 \\
\hline Acenaphthylene & $117 \pm 24$ & $95 \pm 18$ & $99 \pm 4$ & $105 \pm 7$ & 15 \\
\hline Acenaphthene & $111 \pm 5$ & $117 \pm 16$ & $99 \pm 3$ & $103 \pm 6$ & 9 \\
\hline Fluorene & $101 \pm 19$ & $99 \pm 16$ & $96 \pm 4$ & $106 \pm 11$ & 15 \\
\hline Phenanthrene & $88 \pm 16$ & $107 \pm 13$ & $95 \pm 5$ & $113 \pm 17$ & 14 \\
\hline Anthracene & $83 \pm 17$ & $106 \pm 5$ & $99 \pm 2$ & $108 \pm 12$ & 11 \\
\hline Fluoranthene & $93 \pm 11$ & $102 \pm 10$ & $98 \pm 4$ & $110 \pm 15$ & 10 \\
\hline Pyrene & $98 \pm 7$ & $97 \pm 9$ & $95 \pm 5$ & $111 \pm 16$ & 10 \\
\hline Benz[a]anthracene & $100 \pm 9$ & $97 \pm 9$ & $93 \pm 5$ & $110 \pm 12$ & 9 \\
\hline Chrysene & $101 \pm 8$ & $92 \pm 11$ & $98 \pm 3$ & $110 \pm 13$ & 10 \\
\hline Benzo[b]fluoranthene & $103 \pm 14$ & $96 \pm 6$ & $98 \pm 3$ & $112 \pm 20$ & 13 \\
\hline Benzo[k] fluoranthene & $79 \pm 38$ & $101 \pm 6$ & $100 \pm 1$ & $100 \pm 11$ & 20 \\
\hline Benzo[a]pyrene & $106 \pm 10$ & $99 \pm 9$ & $98 \pm 2$ & $105 \pm 18$ & 11 \\
\hline Indeno $[1,2,3$-cd $]$ pyrene & $109 \pm 10$ & $74 \pm 10$ & $96 \pm 2$ & $104 \pm 18$ & 12 \\
\hline Dibenz[a,h]anthracene & $108 \pm 11$ & $92 \pm 8$ & $100 \pm 1$ & $107 \pm 19$ & 12 \\
\hline Benzo[g,h,i]perylene & $107 \pm 14$ & $97 \pm 11$ & $90 \pm 4$ & $111 \pm 17$ & 12 \\
\hline Recovery range (\%) & $79-117$ & $74-117$ & $90-101$ & $101-113$ & \\
\hline RSDs range (\%) & $5-38$ & $6-18$ & $1-6$ & $6-20$ & \\
\hline
\end{tabular}

are considered to be quantitative when ion signal-to-noise $(\mathrm{S} / \mathrm{N}) \geq 3$ with $\pm 20 \%$. All samples met the criteria but having $\mathrm{S} / \mathrm{N}<3$ were considered to be $<\mathrm{LOQ}$, while those failed the criteria were considered as not detected (nd). Method detection limits (LODSs) and limit of quantitation (LOQs) are listed in Table 2.

2.9. Recovery and RSDs. The recovery of $(n=10)$ replicates at two levels ( $1 \mathrm{ng} / \mathrm{g}$ and $10 \mathrm{ng} / \mathrm{g}$ ) is calculated and reported in Table 3. The recovery test was repeated on two different days. The calculated recovery and RSDs (\%) are summarized in Table 3 . The result shows very good recovery and excellent RSDs (\%). The recovery for all sets of 10 replicates was in the average range of $74-117 \%$. The lower spiking level was selected in the test in order to define and to check the capability of the method to detect the PAHs in meat sample at $1 \mathrm{ng} / \mathrm{g}$. The spiking levels covered the entire range, and the recovery did not differ at the lowest and the highest concentrations. Three types of smoked meat were used to perform the recovery test, including beef roasted smoked [1] ; smoked turkey breast [29], and Al-Tag beef M smoked [42]. However, there was no influence on the PAHs determination when using different types of smoked meat.

However, according to Commission Regulation (EC) number 1881/2006 and (EC) 333/2007 [40, 41, 43], the LOD for PAHs in meat is $0.3 \mathrm{ng} / \mathrm{g}$ and the LOQ was $0.9 \mathrm{ng} / \mathrm{g}$ wet weight and the recovery range of the method should range from 50 to $120 \%$, which clearly indicates that the method was validated according to the regulation and complies with the recommendation criteria. The validated QuEChERS method selected for PAHs gives excellent recoveries, repeatability, reproducibility, and sensitivity.

\section{Results and Discussion}

In order to obtain the best recovery of the QuEChERS method. All related parameters were optimized. Results of the optimized parameters are discussed. Quenchers is a method of choice for processing samples because it is quick, easy, and inexpensive. The first step was by hydrating the meat samples, and then extracting with acetonitrile followed by partitioning with salts. Hydration steps are important in QuEChERS extraction in order to make partitioning effective $[37,44]$. Acetonitrile is an effective solvent and can result in low coextracted substances for some matrices [44, 45].

Validation of the method was performed, by checking the spike recoveries for meat samples, and determined in 10 replicates for each of two levels for two different days. Method detection limits and limits of quantitation for all 16 PAHs were determined using 10 blank replicates with calculating the standard deviations (SDs).

The GC-MS in SIM mode was shown for monitoring PAHs at a very low concentration in meat samples. Figure 2 shows the chromatogram obtained in GC-MS (SIM) mode for meat samples (Figure 2(a)) when fortified with 16 PAHs at $50 \mathrm{ng} / \mathrm{g}$ level and for nonfortified sample (Figure 2(b)). The chromatogram separation was clean, excellent, and can be achieved without the effect of the sample matrix interferences.

3.1. Effect of Salts in the Extraction. Magnesium sulfate $\left(\mathrm{MgSO}_{4}\right)$ was used as a drying agent to ensure a phase separation between organic solvent and water. Z-Sep QUE reduces concentration of fat, proteins, and other matrix components. Combination of Z-Sep and $\mathrm{MgSO}_{4}$ effectively removes polar matrix and water. Acetonitrile liquid-liquid partitioning is 


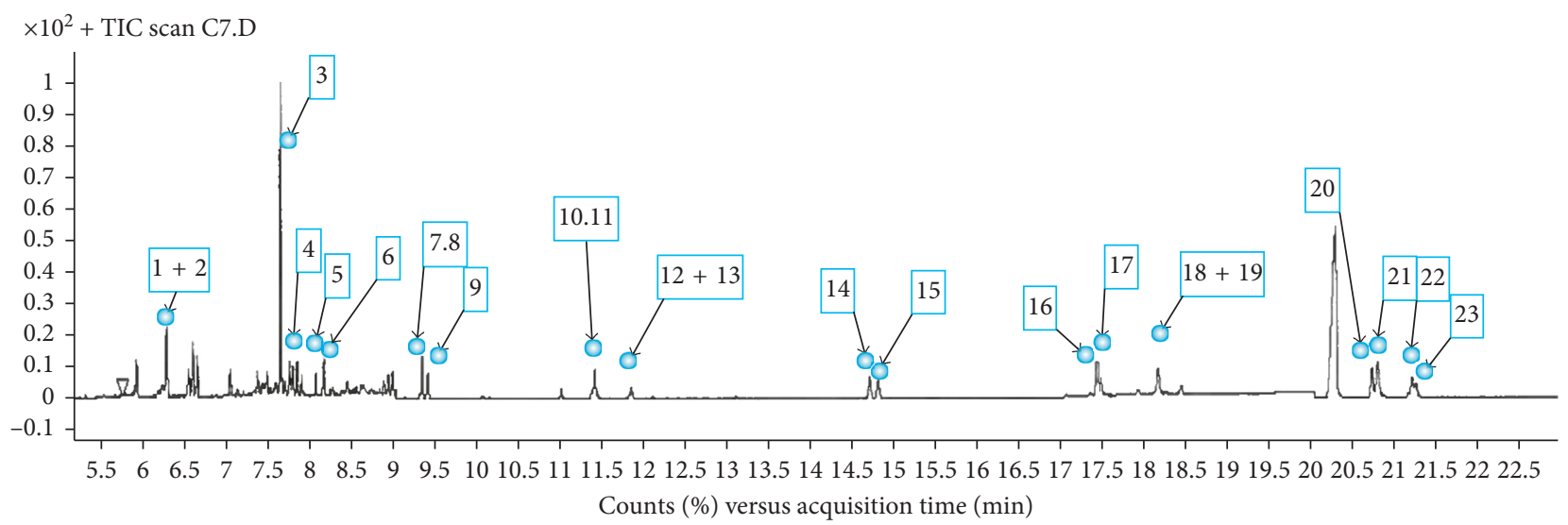

(a)

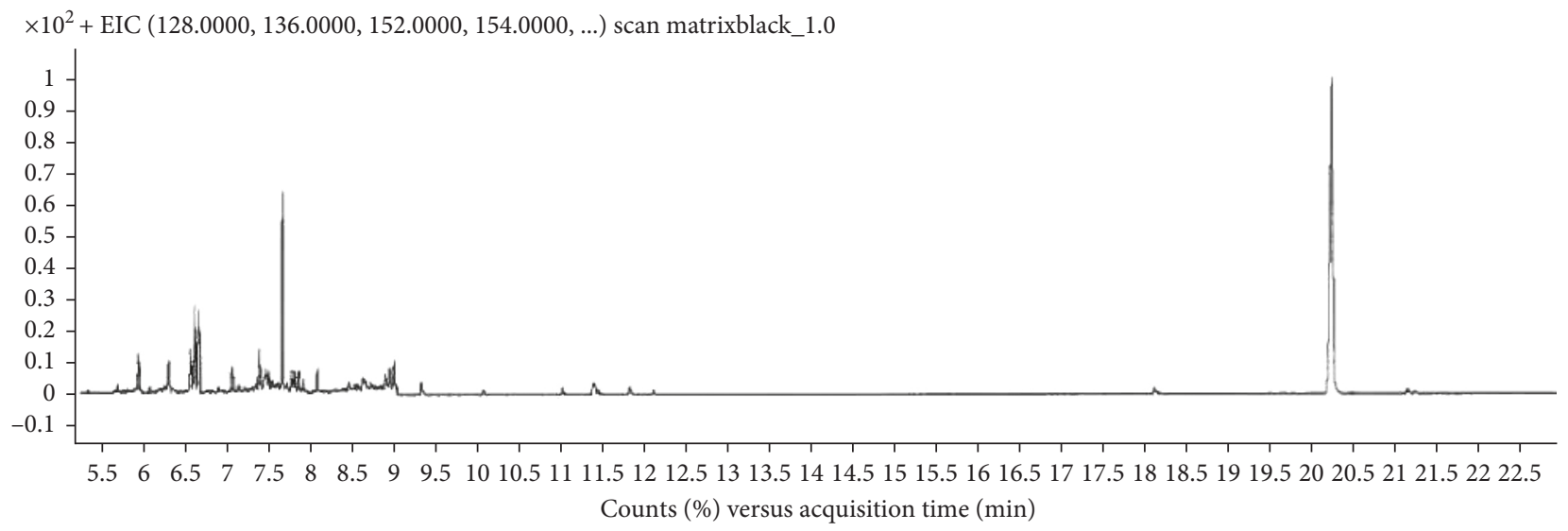

(b)

FIGURE 2: The selected-ion monitoring (SIM) obtained by Z-Sep QUE for meat samples under the selected parameters: (a) spike with 50 ng/g of 16 PAHs and I.S. $(1+2)$ Naphthalene + Naph_d8, (3) acenaphylene_d8, (4) acenaphthylene, (5) acenaphthene, (6) fluorine (7+8) phenanthrene + Phen_d10, (9) anthracene, $(10+11)$ fluoranthene + Fluro_d10, $(12+13)$ pyrene + Pyr_d10, (14) benzo[a]anthracene, (15) chrysene, (16) benzo[b]fluoranthenem, (17) benzo[k]fluoranthene, $(18+19)$ benzo[a]pyrene + B[a]P_d12, $(20)$ indeno[1,2,3-cd]pyrene, $(21)$ dibenz[a,h]anthracene, (22) benzo[g,h,i]perylene_d12, and (23) benzo[g,h,i]perylene. (b) Nonspike meat sample.

done by adding $\mathrm{MgSO}_{4}$ and $\mathrm{NaCl}$, however, $\mathrm{MgSO}_{4}$ and $\mathrm{NaCl}$ generate sample extraction temperature of $45-50^{\circ} \mathrm{C}$ that persisted for the duration of the extraction. $\mathrm{NaCl}$ control the solvent to be removed in contact with the sample, making it to be more effective in the dissolution of analytes and facilitate the partitioning of the analytes from aqueous to the organic layer. The nonpolar PAHs with hydrophobic interaction, with pibond being involved, when extracted with relatively polar solvent (i.e., ACN) pi-bond and linear in geometry gave slightly better extraction. The geometry of the solvent should allow maximum interaction with the analyte besides its polarity.

Increase in salt allows greater phase separation. However, amount of salts used can also have effectiveness on the extraction system. Therefore, the role of the salt is to regulate the polarity of the matrix. Anastassiades et al. [29] showed that the use of $\mathrm{MgSO}_{4}$ to remove the excess of water and to provide an exothermic reaction improves the extraction process.

Furthermore, the addition of salt increases the temperature, lowering the activation energy, decreasing the viscosity of the solvent, and finally increasing the interaction of the solvent matrix [46]. Different amounts of salt were used and the optimal amount of $3.0 \mathrm{~g}$ of $\mathrm{MgSO}_{4}$ and $0.5 \mathrm{~g}$ of $\mathrm{NaCl}$ were selected throughout the experiment which gives the highest intensity response for the extracted PAHs from meat samples.

3.2. Effect of Solvent. As advisable, the solvent must be less expensive, compatible with analytical instrument and environment-friendly [29]. However, acetonitrile (ACN) and ethyl acetate have been largely used to extract polar to nonpolar compounds [42]. The solvent volume can play an essential role in recovery and must be in sufficient quantity to allow the full immersion of the sample into maximum solvent-analyte interaction. Different amounts of ACN were tested: $2.5,5.0,7.5,10$, and $15 \mathrm{ml}$. It was found that the highest peak intensity and the maximum recovery were obtained at $5 \mathrm{ml}$ ACN. ACN provides a cleaner chromatogram and is considered to be one of the most selective solvents, and it has advantage over most other solvents used in QuEChERS technique [29]. However, ACN provide easier 
separators from water compared with other solvents used in QuEChERS in the presence of salts, providing a good phase separation which prevents interaction of polar matrix [36].

3.3. Effect of Centrifuge Time and Speed. The results obtained shows that excellent recovery of PAHs at $10 \mathrm{~min}$, which was chosen as the optimal time for centrifuge. A centrifuge of $3400 \mathrm{rpm}$ was found to be sufficient to obtain a good recovery of PAHs. The centrifuge facilitates the solvent to be more in contact with meat sample, provides more effectiveness in dissolution of the analyte [47], and hence reduces the time required for extraction.

3.4. Effect of Water. For ACN salting out or partitioning to occur, we must have percentage of water associated with the sample. Addition of water creating aqueous environment within the sample reduces the potential for lipids to impact extraction efficiency and minimize the fat extract. Different amounts of water were tested $(2.5,5.0,7.5,10$, and $15 \mathrm{ml})$. It was found that the highest peak intensity and the maximum recovery were obtained with $5 \mathrm{ml}$ and $7.5 \mathrm{ml}$ of water, and by increasing the volume, peak intensity starts decreasing.

3.5. Types of Sorbent Used. Three types of cleaning sorbents were used in the extraction of meat samples. The sorbent has different effect on recovery and selectivity. The effect of sorbent types was evaluated based on the recovery achieved. Z-Sep/C18 (combination of Z-Sep and Discovery ${ }^{\circledR}$ DSC-18 particles) was used, and the recovery varied from 14 to $104 \%$; lower recovery was observed for the PAHs having 5 and 6 rings. Another sorbent that is Z-Sep+ (dual bonded C18 and zirconium silica) was tested, and the recovery ranged from 46 to $126 \%$, and the lower recovery was observed for the PAHs having 6 rings. The lower recoveries of PAHs having 5 and 6 rings could be due to limited solubility of these compounds in acetonitrile. However, the Z-Sep is a zirconium-coated silica (recommended for highly hydrophobic analytes such as PAHs and PCBs) yielded the highest average recoveries, and a few matrix interferences were observed in the first few minutes of the GC-MS run. Therefore, Z-Sep QUE was used throughout the experiment.

3.6. Analysis of Real Samples. Seven out of 16 PAHs have been categorized as probable human carcinogens. These are benzo[a]anthracene, benzo[b]fluoranthene, benzo[k]fluoranthene, chrysene, benzo[a]pyrene, dibenzo[a,h]anthracene, and indeno[1,2,3-cd]pyrene [26, 48]. The European Union has setup maximum levels of $2 \mathrm{ng} / \mathrm{g}$ wet weight for benzo[a]pyrene and considered to be a marker for carcinogenic risk [49]. However, the European Food Safety Authority [50] declared that benzo[a]pyrene is not a suitable marker for the occurrence and toxicity of PAHs in food. In 2012, four groups of PAHs were considered to provide many values to carcinogenicity, and they are benzo[a]anthracene, benzo[b]fluoranthene, chrysene, and benzo[a]pyrene [51].

In order to verify the effectiveness of the method, different types of smoked meat samples $(n=30)$ were analyzed using the optimal parameters. The results of the smoked meat samples are presented in Table 4.

Noncarcinogenic PAHs (NAPH, ACNY, CAN, FL, PHEN, ANTH, FLUO, and PYR) are accounted to be at proportion more than $70 \%$ of the total PAHs detected in meat samples. It is obvious that the noncarcinogenic PAHs in smoked meat samples are predominant. The genotoxic PAH8 was found to be more than $20 \%$ relative percentage of the total PAHs detected and the most predominant PAHs was $\mathrm{B}[\mathrm{a}] \mathrm{P}$ and found to be less than $5 \%$ relative percentage.

From Table 5, naphthalene, acenaphthene, fluorine, and phenanthrene (noncarcinogenic PAHs) shows the highest mean concentration of $4.78 \mathrm{ng} / \mathrm{g}, 25.17 \mathrm{ng} / \mathrm{g}, 1.97 \mathrm{ng} / \mathrm{g}$, and $1.45 \mathrm{ng} / \mathrm{g}$, respectively, whereas the lowest concentration was found for chrysene, $\mathrm{I}[\mathrm{cd}] \mathrm{P}$ and $\mathrm{D}[\mathrm{ah}] \mathrm{A}$, comprising less than $5.0 \%$ of the total PAH concentration with respect to PAH8. B [a]P $(0.90 \mathrm{ng} / \mathrm{g} ;<5.0 \%)$ with a frequent detection more than $20 \%$, and $\mathrm{I}[\mathrm{cd}] \mathrm{P}$ was found to be the second highest detected PAHs with more than $15 \%$. From the values reported by EFSA, the highest mean concentration for individual PAH8 was $0.47 \mathrm{ng} / \mathrm{g}$ and $0.29 \mathrm{ng} / \mathrm{g}$ for $\mathrm{CHRY}$ and B[a]P, respectively, in grilled meat samples in EU countries [50]. However, the mean concentration for the sum of PAH8 detected in this method was $1.82 \mathrm{ng} / \mathrm{g}$, which is close to the reported mean concentration ( $1.77 \mathrm{ng} / \mathrm{g}$ ) by EFSA [50]. B[a]P was detected in $23 \%$ of the total sample analyzed, and the mean concentration was $0.90 \mathrm{ng} / \mathrm{g}$, which is below the maximum allowable limit adopted by the European Union (EU) for B[a]P ( $5 \mathrm{ng} / \mathrm{g}$ ) in smoked meat $[43,52]$. The maximum limits for the rest of carcinogenic PAHs were not yet established. The mean concentration of PAH8 and $\sum \mathrm{B}[\mathrm{a}]$ Peq, shows relatively low levels of genotoxic PAHs in smoked meat. The European countries set a maximum level of $2 \mathrm{ng} / \mathrm{g}$ for individual PAH and $5 \mathrm{ng} / \mathrm{g}$ for the sum of PAH8 in olive residual oil [53].

$\mathrm{B}[\mathrm{a}] \mathrm{P}$ content was found to be with a maximum of $3.63 \mathrm{ng} / \mathrm{g}$, which represents a factor below the level permitted by EU ( $5 \mathrm{ng} / \mathrm{g})$. However, the mean $\mathrm{BaP}$ for all analyzed samples was $0.90 \mathrm{ng} / \mathrm{g}$, which is also far below the permitted limits.

EFSA declared that the PAH4 or PAH8 are significantly more effective indicator of PAHs occurrence in food than the concentration of $\mathrm{B}[\mathrm{a}] \mathrm{P}$ alone [50]. However, in relation with PAH4, the total concentration calculated for different smoked meat was $10.84 \mathrm{ng} / \mathrm{g}$, and for PAH8, the total concentration was $14.54 \mathrm{ng} / \mathrm{g}$ (Table 5). $\mathrm{B}[\mathrm{b}] \mathrm{F}$ and $\mathrm{B}$ [ghi] $\mathrm{P}$ was not found in all tested smoked samples.

3.7. Method Uncertainty. Repeatability of the analysis was performed for two levels on different days: ten replicates for each level and the standard deviation were defined. The uncertainty derived from repeatability is calculated by the following equation:

$$
U(\text { rep })=\frac{\mathrm{RSD}}{V_{n}},
$$

where RSD is the relative standard deviation and $n$ is the number of repetition $(n=10) . U(\mathrm{rec})$ is calculated and found to be equal $3.32 \% . U(p)$ is the relative standard 
TABle 4: : Levels of individual PAHs detected in different samples $(\mathrm{ng} / \mathrm{g})(n=2)$.

\begin{tabular}{|c|c|c|c|c|c|c|c|c|c|c|c|c|c|}
\hline PAHs & Nap & $\mathrm{ACN}$ & FL & PHEN & ANTH & FLUO & PYR & $\mathrm{B}[\mathrm{a}] \mathrm{A}$ & $\mathrm{CHR}$ & $\mathrm{B}[\mathrm{a}] \mathrm{P}$ & I_cd P & $\mathrm{DB}[\mathrm{a}, \mathrm{h}] \mathrm{A}$ & $\sum \mathrm{PAHs}$ \\
\hline Al-Tag tky smoked breast & nd & nd & 1.58 & nd & 1.00 & nd & nd & nd & nd & 0.39 & nd & nd & 2.97 \\
\hline Prime tky smkd breast strip & nd & nd & 1.73 & 1.45 & nd & 0.77 & 1.05 & nd & nd & 0.36 & nd & 0.63 & 6.00 \\
\hline Prime chk smoked breast & nd & nd & 1.47 & nd & nd & nd & 0.51 & nd & nd & nd & nd & nd & 1.98 \\
\hline Gourmet smoked chicken roll & 2.86 & nd & nd & nd & nd & 0.77 & 1.13 & nd & nd & nd & nd & nd & 4.76 \\
\hline Gourmet smoked turkey & nd & nd & nd & nd & nd & nd & nd & nd & nd & 0.35 & nd & nd & 0.35 \\
\hline 5 yildiz smoked turkey breast & nd & nd & 1.22 & nd & nd & nd & nd & nd & nd & nd & nd & nd & 1.22 \\
\hline Volys tky smoked breast & 5.73 & 25.17 & 2.26 & nd & nd & nd & nd & nd & nd & nd & 0.75 & nd & 33.90 \\
\hline Siniora tky smoked breast & nd & nd & nd & nd & nd & 0.60 & nd & nd & nd & nd & 0.87 & nd & 1.47 \\
\hline Euro gourmet smoked chicken & nd & nd & 3.34 & nd & nd & nd & nd & nd & nd & nd & 0.63 & nd & 3.97 \\
\hline Volys tky smoked strips & 4.70 & nd & 1.63 & nd & nd & 0.59 & 0.84 & nd & nd & nd & nd & nd & 7.76 \\
\hline Al tag chk m plain & nd & nd & 1.91 & nd & nd & nd & nd & nd & nd & nd & nd & nd & 1.91 \\
\hline Al-Tag tky roast & 7.86 & nd & 3.84 & nd & nd & nd & nd & nd & nd & nd & 0.41 & nd & 12.11 \\
\hline Volys & nd & nd & nd & nd & nd & nd & nd & nd & 0.53 & nd & nd & nd & 0.53 \\
\hline kn breast blk & nd & nd & nd & nd & nd & nd & nd & nd & nd & 3.63 & nd & nd & 3.63 \\
\hline Gourmet ckn plain mortadella & nd & nd & nd & nd & nd & nd & nd & nd & nd & nd & nd & nd & nd \\
\hline Aia tky oven breast low fat & nd & nd & nd & nd & nd & nd & nd & nd & nd & nd & nd & nd & nd \\
\hline tky breast & 3.49 & nd & nd & nd & nd & nd & nd & nd & nd & nd & nd & nd & 3.49 \\
\hline Aia chk breast low fat & nd & nd & nd & nd & nd & nd & nd & nd & nd & nd & nd & nd & nd \\
\hline Euro gourmet rstd chicken fi & 3.22 & nd & nd & nd & nd & nd & nd & nd & nd & nd & nd & nd & 3.22 \\
\hline Aia tky roast thigh & 3.65 & nd & nd & nd & nd & nd & nd & nd & nd & nd & nd & nd & 3.65 \\
\hline Al-Tag beef $\mathrm{m}$ smoke & nd & nd & nd & nd & nd & nd & nd & nd & nd & nd & 0.42 & nd & 0.42 \\
\hline Al-Tag & nd & nd & nd & nd & 0.36 & nd & 0.52 & 1.15 & 0.94 & 0.48 & nd & nd & 3.44 \\
\hline Siniora pastrami w/pe & 4.07 & nd & nd & nd & nd & nd & nd & nd & nd & nd & nd & nd & 4.07 \\
\hline Bibi smoke turkey bre & nd & nd & nd & nd & nd & nd & nd & nd & nd & nd & nd & nd & nd \\
\hline Sams finest tky bst $r$ & & nd & 1.38 & nd & nd & nd & nd & nd & nd & nd & nc & nd & 1.38 \\
\hline Sams & 7.42 & nd & 1.54 & nd & nd & nd & nd & nd & nd & 0.37 & nd & nd & 9.32 \\
\hline Bibi chick & nd & nd & 1.71 & nd & nd & nd & nd & nd & & nd & nd & nd & 1.71 \\
\hline 5 yildiz turkey mortad & nd & nd & nd & nd & nd & nd & nd & 0.91 & 0.58 & 0.71 & nd & nd & 2.20 \\
\hline 5 yildiz & nd & nd & nd & nd & nd & nd & nd & nd & nd & nd & nd & nd & nd \\
\hline Gourmet beed pastrami & & nd & nd & nd & nd & nd & nd & nd & 0.45 & nd & nd & nd & 0.45 \\
\hline$\sum \mathrm{PAHs}$ & 43.00 & 25.17 & 23.61 & 1.45 & 1.36 & 2.73 & 4.05 & 2.06 & 2.49 & 6.29 & 3.07 & 0.63 & - \\
\hline Averg. concentration & 4.78 & 25.17 & 1.97 & 1.45 & 0.68 & 0.68 & 0.81 & 1.03 & 0.62 & 0.90 & 0.61 & 0.63 & - \\
\hline SD & 1.83 & - & 0.84 & - & - & 0.1 & 0.29 & 0.16 & 0.22 & 1.3 & 0.2 & - & - \\
\hline Frequently detected (\%) & 30.00 & 3.33 & 40.00 & 3.33 & 6.67 & 13.33 & 16.67 & 6.67 & 13.33 & 23.33 & 16.67 & 3.33 & - \\
\hline
\end{tabular}

Note: nd refers to values below LODs.

TABle 5: Mean concentration of PAHs, $\sum$ PAHs, TEF, TEQ ( $\left.\sum \mathrm{B}[\mathrm{a}] \mathrm{Peq}\right)$, and relative \% to $\sum \mathrm{PAHs}$ (ng/g wet/wt).

\begin{tabular}{|c|c|c|c|c|c|c|c|c|}
\hline Compounds & $\sum$ Indiv. PAHs & $\min$ & $\max$ & Mean $\sum$ PAHs & TEF & TEQ & Relative $\%$ to $\sum$ PAHs & Frequent detection (\%) \\
\hline Naphthalene & 43.00 & 2.86 & 7.86 & 4.78 & 0.000 & 0.000 & 32.82 & 30.00 \\
\hline Acenaphthene & 25.17 & 25.17 & 25.17 & 25.17 & 0.001 & 0.025 & 19.22 & 3.33 \\
\hline Fluorene & 23.61 & 1.22 & 3.84 & 1.97 & 0.001 & 0.024 & 18.02 & 40.00 \\
\hline Phenanthrene & 1.45 & 1.45 & 1.45 & 1.45 & 0.001 & 0.001 & 1.11 & 3.33 \\
\hline Anthracene & 1.36 & 0.36 & 0.36 & 0.68 & 0.010 & 0.014 & 1.04 & 6.67 \\
\hline Fluoranthene & 2.73 & 0.59 & 0.77 & 0.68 & 0.010 & 0.027 & 2.08 & 13.33 \\
\hline Pyrene & 4.05 & 0.51 & 1.13 & 0.81 & 0.001 & 0.004 & 3.09 & 16.67 \\
\hline Benz[a] anthracene & 2.06 & 0.91 & 1.15 & 1.03 & 0.100 & 0.206 & 1.57 & 6.67 \\
\hline Chrysene & 2.49 & 0.45 & 0.94 & 0.62 & 0.010 & 0.025 & 1.90 & 13.33 \\
\hline Benzo[a]pyrene & 6.29 & 0.35 & 3.63 & 0.90 & 1.000 & 6.289 & 4.80 & 23.33 \\
\hline Indeno[1,2,3-cd]pyrene & 3.07 & 0.41 & 0.87 & 0.61 & 0.100 & 0.307 & 2.35 & 16.67 \\
\hline Dibenz[a,h] anthracene & 0.63 & 0.63 & 0.63 & 0.63 & 1.000 & 0.625 & 0.48 & 3.33 \\
\hline$\sum \mathrm{PAHs}$ & 115.92 & & & & & & & \\
\hline$\sum \mathrm{PAH}^{*}$ & 14.54 & 1.82 & & & & & & \\
\hline$\sum \mathrm{PAH} 4^{* *}$ & 10.84 & 2.71 & & & & & & \\
\hline$\sum \mathrm{LMW}^{* * *}$ & 94.59 & 15.77 & & & & & & \\
\hline$\sum \mathrm{HMW}^{* * * *}$ & 21.32 & 2.13 & & & & & & \\
\hline Mean of the $\sum$ PAHs & & 3.71 & & & & & & \\
\hline
\end{tabular}

${ }^{*} \mathrm{~B}[\mathrm{a}] \mathrm{A}$, Chry, B[b]F, B[k]F, B[a]P, Ind[1,2,3-cd]pyrene, Dibenz[a,h]A, and Benzo[ghi]P. ${ }^{* *} \mathrm{~B}[\mathrm{a}] \mathrm{A}$, Chry, B[b]F and B[a]P. ${ }^{* * *}$ Low molecular weight (LMW): Naph, ACNY, ACN, Fl, Phen and Anth. ${ }^{* * * *}$ High molecular weight (HMW): Fluor, Pyr, B[a]A, Chry, B[b]F, B[k]F, B[a]P, Ind[1,2,3-cd]pyrene, Dibenz[a,h] $\mathrm{A}$, and Benzo[ghi]P. 
uncertainty due to precision and expressed as RSDs (\%) and found to be $11 \%$.

Standard uncertainty of the stock standard purity (\%) $\left(U_{\mathrm{STD}}\right)$ is 0.00577 and the standard uncertainty of the internal standard purity $(\%)\left(U_{\text {INSTD }}\right)$ is 0.00576 .

The combined uncertainty $(U(c))$ is calculated by the following equation:

$$
\begin{aligned}
U(\mathrm{c})= & \text { square } \operatorname{root}(U(\mathrm{p}))^{2}+(U(\mathrm{rec}))^{2}+(U(\mathrm{STD})) \\
& +(U(\mathrm{INSTD}))=11.49 \% .
\end{aligned}
$$

Expanded uncertainty is calculated by multiplying the combined uncertainty by a coverage factor $k(k=2$ at $95 \%$ confidence level) as follows:

$$
\begin{aligned}
& U_{\text {exp }}=U_{c} * K, \\
& U_{\text {exp }}=22.98 \% .
\end{aligned}
$$

\section{Conclusions}

This study reports for the first time the application of Quenchers for the determination of PAHs in smoked meat samples in Qatar. However, this study reports the levels of $\mathrm{BaP}, \mathrm{PAH}$, $\sum \mathrm{LMW}, \sum \mathrm{B}[\mathrm{a}] \mathrm{Peq}, \sum \mathrm{PAHs}$, and $\sum \mathrm{HMW}$ in smoked meat items commonly consumed in the Gulf countries. The levels of PAHs in this study found to be not exceeding the maximum levels (according to a regulation of European Commission (EU) no. 835/2011) for PAHs determined in samples [51].

The developed method and performance characteristics are in accordance with the required in legislation. The proposed EU method which defined a range of acceptable recovery between 50 and $120 \%$, with a maximum LODS and LOQ of $0.3 \mathrm{ng} / \mathrm{g}$ and $0.9 \mathrm{ng} / \mathrm{g}$, respectively, for B[a]P in food $[40,41]$.

\section{Conflicts of Interest}

The authors declare that they have no conflicts of interest.

\section{References}

[1] M. J. Agerstad and K. Skog, "Review genotoxicity of heatprocessed foods," Mutation Research, vol. 574, pp. 156-172, 2005.

[2] European Commission Scientific Committee on Foods, Opinion of the Scientific Committee on Food on the Risks to Human Health of Polycyclic Aromatic Hydrocarbons in Food, European Commission Scientific Committee on Foods, Brussels, Belgium, 2002.

[3] FAO/WHO Expert Committee on Food Additives, Meeting \& World Health Organization, Evaluation of Certain Food Additives: Sixty-Fourth Meeting, 2005.

[4] I. C. Nisbet and P. K. LaGoy, "Toxic equivalency factors (TEFs) for polycyclic aromatic hydrocarbons (PAHs)," Regulatory Toxicology and Pharmacology, vol. 16, no. 3, pp. 290-300, 1992.

[5] Joint FAO/WHO Expert Committee on Food Additives and contaminants in WHO Food Additive Report Series, International
Program on Chemical Safety, Vol. 28, World Health Organization, Geneva, Switzerland, 1991.

[6] J. M. Llobet, G. Falco, A. Bocio, and J. L. Domingo, "Exposure to polycyclic aromatic hydrocarbons through consumption of edible marine species in Catalonia, Spain," Journal of Food Protection, vol. 69, no. 10, pp. 2493-2499, 2006.

[7] World Health Organization, Selected Non-Heterocyclic Polycyclic Aromatic Hydrocarbons. Environmental Health Criteia No. 202, WHO, Geneva, Switzerland, 1998.

[8] M. Howsam, K. C. Jones, and P. Ineson, "PAHs associated with the leaves of three deciduous tree species. I-concentrations and profiles," Environmental Pollution, vol. 108, no. 3, pp. 413-424, 2000.

[9] V. A. Du Four, N. Van Larebeke, and C. R. Janssen, "Genotoxic and mutagenic activity of environmental air samples in Flanders, Belgium," Mutation Research/Genetic Toxicology and Environmental Mutagenesis, vol. 558, no. 1-2, pp. 155-167, 2004.

[10] D. H. Phillips, "Polycyclic aromatic hydrocarbons in the diet," Mutation Research/Genetic Toxicology and Environmental Mutagenesis, vol. 443, no. 1, pp. 139-147, 1999.

[11] European Commission, "Commission recommendation 2005/108/EC of 4 February 2005 on the further investigation into the levels of polycyclic aromatic hydrocarbons in certain foods," Official Journal of the European Union, vol. L34, pp. 43-45, 2005.

[12] P. Plaza-Bolaños, A. G. Frenich, and J. L. M. Vidal, "Polycyclic aromatic hydrocarbons in food and beverages. Analytical methods and trends," Journal of Chromatography A, vol. 1217, no. 41, pp. 6303-6326, 2010.

[13] B. Veyrand, A. Brosseaud, L. Sarcher et al., "Innovative method for determination of 19 polycyclic aromatic hydrocarbons in food and oil samples using gas chromatography coupled to tandem mass spectrometry based on an isotope dilution approach," Journal of Chromatography A, vol. 1149, no. 2, pp. 333-344, 2007.

[14] A. Zachara, D. Gałkowska, and L. Juszczak, "Contamination of smoked meat and fish products from Polish market with polycyclic aromatic hydrocarbons," Food Control, vol. 80, pp. 45-51, 2017.

[15] M. Kamankesh, A. Mohammadi, H. Hosseini, and Z. M. Tehrani, "Rapid determination of polycyclic aromatic hydrocarbons in grilled meat using microwave-assisted extraction and dispersive liquid-liquid microextraction coupled to gas chromatography-mass spectrometry," Meat Science, vol. 103, pp. 61-67, 2015.

[16] V. Ghasemzadeh-Mohammadi, A. Mohammadi, M. Hashemi, R. Khaksar, and P. Haratian, "Microwave-assisted extraction and dispersive liquid-liquid microextraction followed by gas chromatography-mass spectrometry for isolation and determination of polycyclic aromatic hydrocarbons in smoked fish," Journal of Chromatography A, vol. 1237, pp. 30-36, 2012.

[17] E. Ledesma, M. Rendueles, and M. Díaz, "Spanish smoked meat products: benzo (a) pyrene $(\mathrm{BaP})$ contamination and moisture," Journal of Food Composition and Analysis, vol. 37, pp. 87-94, 2015.

[18] C. Santos, A. Gomes, and L. C. Roseiro, "Polycyclic aromatic hydrocarbons incidence in Portuguese traditional smoked meat products," Food and Chemical Toxicology, vol. 49, no. 9, pp. 2343-2347, 2011.

[19] A. Hitzel, M. Pöhlmann, F. Schwägele, K. Speer, and W. Jira, "Polycyclic aromatic hydrocarbons (PAH) and phenolic substances in meat products smoked with different types of wood and smoking spices," Food Chemistry, vol. 139, no. 1, pp. 955-962, 2013. 
[20] S. Wretling, A. Eriksson, G. A. Eskhult, and B. Larsson, "Polycyclic aromatic hydrocarbons (PAHs) in Swedish smoked meat and fish," Journal of Food Composition and Analysis, vol. 23, no. 3, pp. 264-272, 2010.

[21] B. Kartalovic, D. Okanovic, J. Babic, V. Djordjevic, S. Jankovic, and M. Cirkovic, "Polycyclic aromatic hydrocarbons in smoked ham," Procedia Food Science, vol. 5, pp. 144-147, 2015.

[22] J. Li, H. Dong, X. Li, B. Han, C. Zhu, and D. Zhang, "Quantitatively assessing the health risk of exposure to PAHs from intake of smoked meats," Ecotoxicology and Environmental Safety, vol. 124, pp. 91-95, 2016.

[23] P. Šimko, "Factors affecting elimination of polycyclic aromatic hydrocarbons from smoked meat foods and liquid smoke flavorings," Molecular Nutrition and Food Research, vol. 49, no. 7, pp. 637-647, 2005.

[24] J. Fismes, C. Schwartz, C. Perrin-Ganier, J. L. Morel, A. M. Charissou, and M. J. Jourdain, "Risk of contamination for edible vegetables growing on soils polluted by polycyclic aromatic hydrocarbons," Polycyclic Aromatic Compounds, vol. 24, no. 4-5, pp. 827-836, 2004.

[25] R. M. Smith, "Before the injection-modern methods of sample preparation for separation techniques," Journal of Chromatography A, vol. 1000, no. 1, pp. 3-27, 2003.

[26] USEPA (US Environmental Protection Agency), Fedral Register, 59 FR 1788, U.S. Environmental Protection Agency, Washington, DC, USA, 1994.

[27] U.S. Environmental Protection Agency, Florisil Cleanup, SW846: Method 3620c, Revision 3, U.S. Environmental Protection Agency, Washington, DC, USA, 2007.

[28] U.S. Environmental Protection Agency, Organic Extraction and Sample Preparation, SW-846: Method 3630c, Revision 3, U.S. Environmental Protection Agency, Washington, DC, USA, 1996.

[29] M. Anastassiades, S. J. Lehotay, D. Štajnbaher, and F. J. Schenck, "Fast and easy multiresidue method employing acetonitrile extraction/partitioning and "dispersive solidphase extraction" for the determination of pesticide residues in produce," Journal of AOAC International, vol. 86, no. 2, pp. 412-431, 2003.

[30] S. J. Lehotay, K. Maštovská, and S. J. Yun, "Evaluation of two fast and easy methods for pesticide residue analysis in fatty food matrixes," Journal of AOAC International, vol. 88, no. 2, pp. 630-638, 2005.

[31] H. R. Norli, A. Christiansen, and E. Deribe, "Application of QuEChERS method for extraction of selected persistent organic pollutants in fish tissue and analysis by gas chromatography mass spectrometry," Journal of Chromatography A, vol. 1218, no. 41, pp. 7234-7241, 2011.

[32] D. F. Rawn, J. Judge, and V. Roscoe, "Application of the QuEChERS method for the analysis of pyrethrins and pyrethroids in fish tissues," Analytical and Bioanalytical Chemistry, vol. 397, no. 6, pp. 2525-2531, 2010.

[33] Y. Sapozhnikova and S. J. Lehotay, "Multi-class, multi-residue analysis of pesticides, polychlorinated biphenyls, polycyclic aromatic hydrocarbons, polybrominated diphenyl ethers and novel flame retardants in fish using fast, low-pressure gas chromatography-tandem mass spectrometry," Analytica Chimica Acta, vol. 758, pp. 80-92, 2013.

[34] N. Omar, J. Bakar, and K. Muhammad, "Determination of organochlorine pesticides in shrimp by gas chromatographymass spectrometry using a modified QuEChERS approach," Food Control, vol. 34, no. 2, pp. 318-322, 2013.

[35] A. Sadowska-Rociek, M. Surma, and E. Cieślik, "Comparison of different modifications on QuEChERS sample preparation method for PAHs determination in black, green, red and white tea," Environmental Science and Pollution Research, vol. 21, no. 2, pp. 1326-1338, 2014.

[36] C. Diez, W. A. Traag, P. Zommer, P. Marinero, and J. Atienza, "Comparison of an acetonitrile extraction/partitioning and "dispersive solid-phase extraction" method with classical multi-residue methods for the extraction of herbicide residues in barley samples," Journal of Chromatography A, vol. 1131, no. 1-2, pp. 11-23, 2006.

[37] K. Maštovská and S. J. Lehotay, "Evaluation of common organic solvents for gas chromatographic analysis and stability of multiclass pesticide residues," Journal of Chromatography A, vol. 1040, no. 2, pp. 259-272, 2004.

[38] F. J. Schenck, P. Callery, P. M. Gannett, J. R. Daft, and S. J. Lehotay, "Comparison of magnesium sulfate and sodium sulfate for removal of water from pesticide extracts of foods," Journal of AOAC International, vol. 85, no. 5, pp. 1177-1180, 2002.

[39] A. Müller, E. Björklund, and C. von Holst, "On-line clean-up of pressurized liquid extracts for the determination of polychlorinated biphenyls in feeding stuffs and food matrices using gas chromatography-mass spectrometry," Journal of Chromatography A, vol. 925, no. 1, pp. 197-205, 2001.

[40] European Union, "Commission regulation (EC) no. 401/2006 laying down the methods of sampling and analysis for the official control of the levels of mycotoxins in foodstuffs," Official Journal of the European Union, vol. L70, pp. 12-34, 2007.

[41] European Union, Official Journal of the European Union L88, European Union, Brussels, Belgium, 2007.

[42] R. Carabias-Martínez, E. Rodríguez-Gonzalo, P. Revilla-Ruiz, and J. Hernández-Méndez, "Pressurized liquid extraction in the analysis of food and biological samples," Journal of Chromatography A, vol. 1089, no. 1-2, pp. 1-17, 2005.

[43] European Commission, "Setting maximum levels for certain contaminants in foodstuffs," Official Journal of the European Union, vol. 364, no. 5, 2006.

[44] I. R. Pizzutti, A. de Kok, M. Hiemstra, C. Wickert, and O. D. Prestes, "Method validation and comparison of acetonitrile and acetone extraction for the analysis of 169 pesticides in soya grain by liquid chromatography-tandem mass spectrometry," Journal of Chromatography A, vol. 1216, no. 21, pp. 4539-4552, 2009.

[45] Z. Huang, Y. Li, B. Chen, and S. Yao, "Simultaneous determination of 102 pesticide residues in Chinese teas by gas chromatography-mass spectrometry," Journal of Chromatography B, vol. 853, no. 1, pp. 154-162, 2007.

[46] B. E. Richter, B. A. Jones, J. L. Ezzell, N. L. Porter, N. Avdalovic, and C. Pohl, "Accelerated solvent extraction: a technique for sample preparation," Analytical Chemistry, vol. 68, no. 6, pp. 1033-1039, 1996.

[47] A. Kouzayha, M. Al Iskandarani, S. Mokh, A. R. Rabaa, H. Budzinski, and F. Jaber, "Optimization of a solid-phase extraction method using centrifugation for the determination of 16 polycyclic aromatic hydrocarbons in water," Journal of Agricultural and Food Chemistry, vol. 59, no. 14, pp. 75927600, 2011.

[48] U.S. Environmental Protection Agency, Organic Extraction and Sample Preparation, SW-846: Method 3640a, Revision 1, U.S. Environmental Protection Agency, Washington, DC, USA, 1994.

[49] European Commission, "Commission regulation no 208/ 2005: regards polycyclic aromatic hydrocarbons," Official Journal of the European Union, vol. 134, pp. 3-5, 2005. 
[50] EFSA, "Scientific opinion of the panel on contaminants in the food Chain on a request from the European Commission on Polycyclic Aromatic Hydrocarbons in Food," EFSA Journal, vol. 724, pp. 1-114, 2008.

[51] European Commission (EC), European Commission Regulation: O.J. (L835), European Commission, Brussels, Belgium, 2011.

[52] European Commission, Setting Maximum Levels for Certain Contaminants in Foodstuffs, Commission Regulation (EU) No. 1881/2006, European Commission, Brussels, Belgium, 2006.

[53] S. Moret, G. Purcaro, and L. S. Conte, "Polycyclic aromatic hydrocarbons in vegetable oils from canned foods," European Journal of Lipid Science and Technology, vol. 107, no. 7-8, pp. 488-496, 2005. 

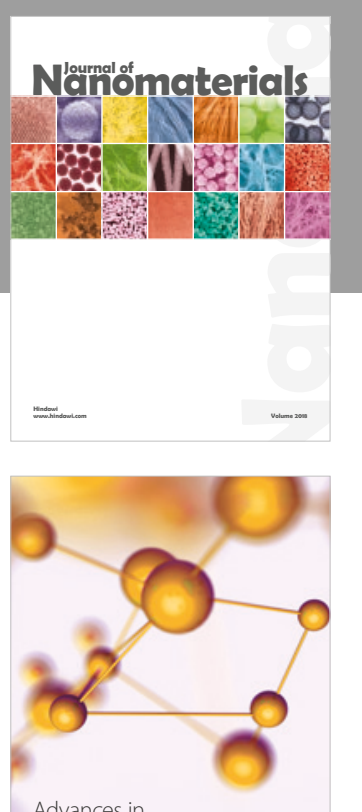

Physical Chemistry
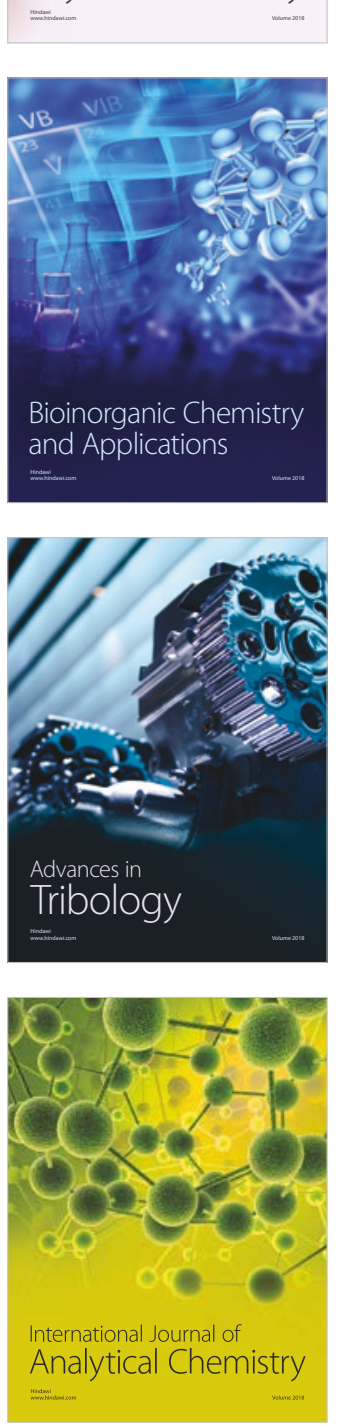

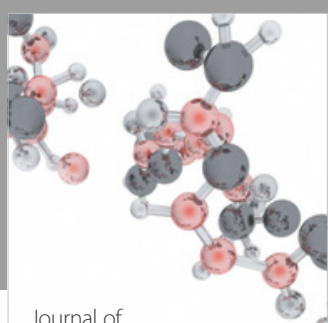

Analytical Methods

in Chemistry

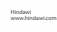

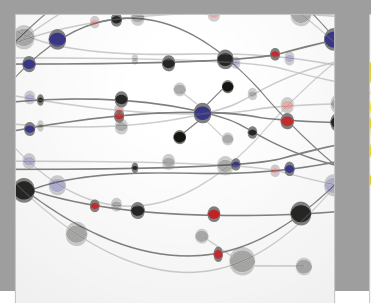

The Scientific World Journal

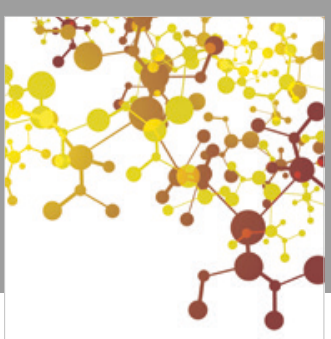

Journal of

Applied Chemistry
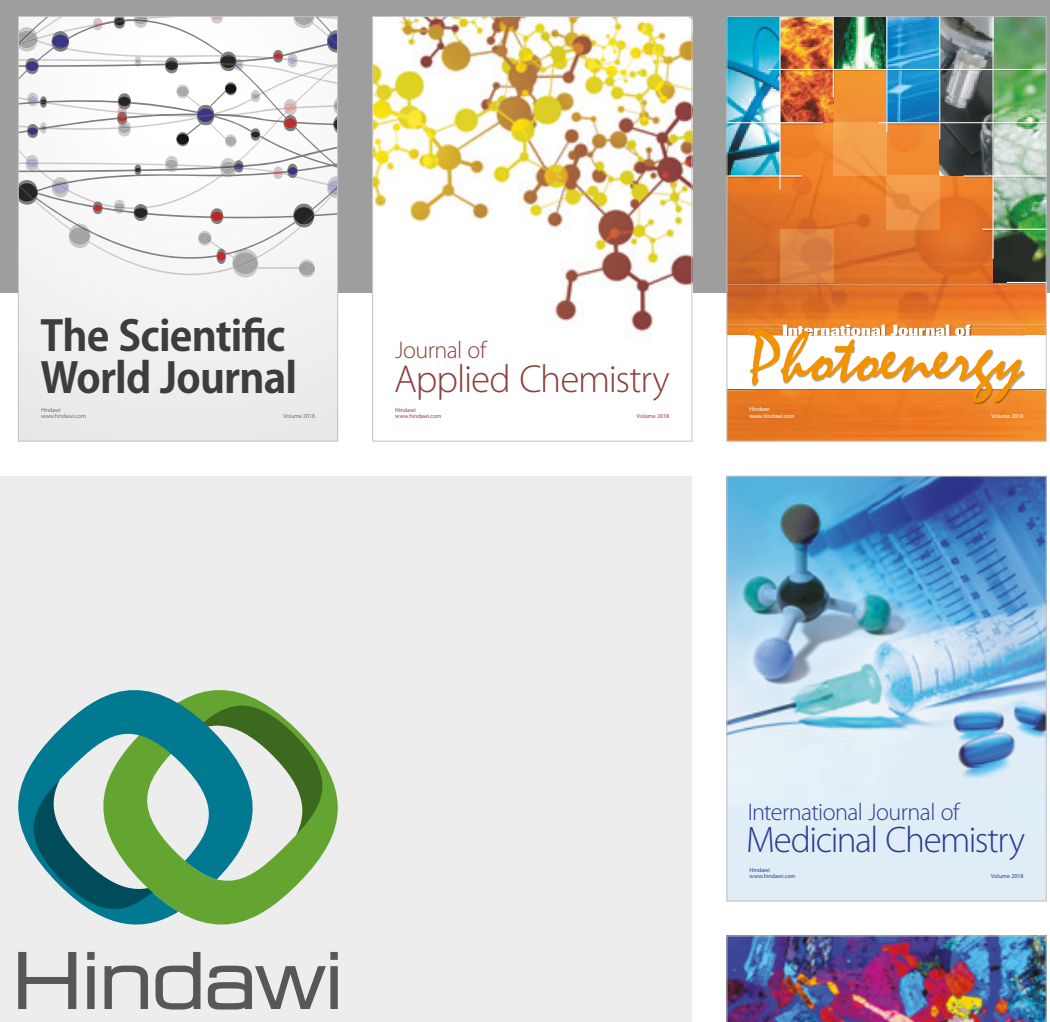

Submit your manuscripts at

www.hindawi.com
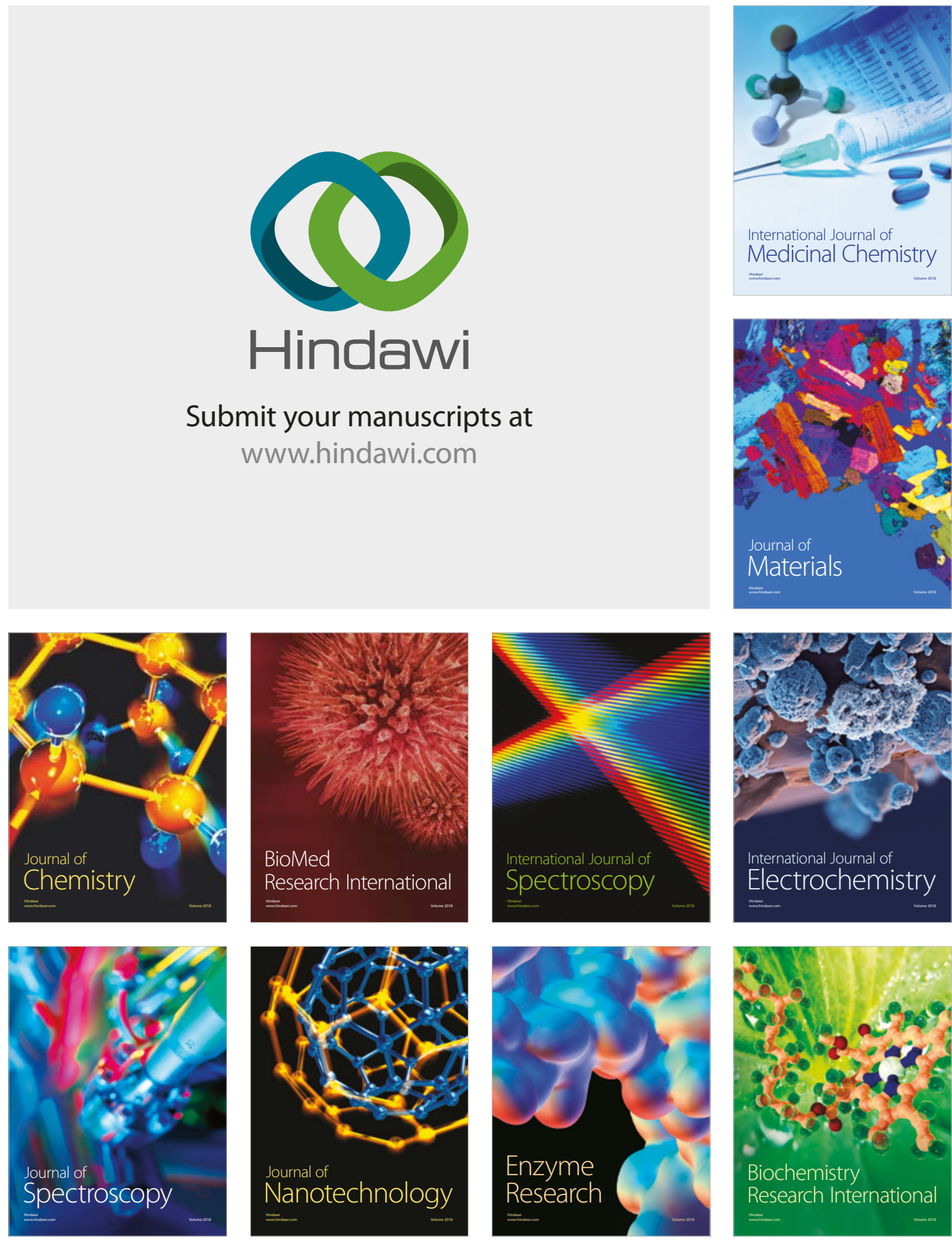
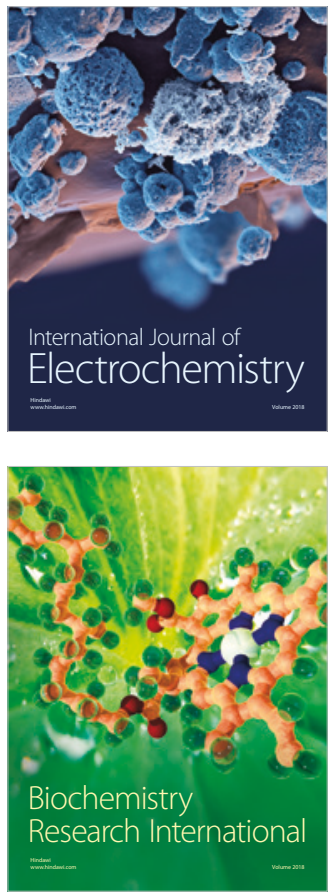